\title{
Heavy Metals Adsorption on Cellulosic Materials from Agricultural Waste
}

\author{
*ONIGBINDE, MO; OKEKE, SR
}

\author{
Department of Chemical Sciences, Samuel Adegboyega University, Ogwa, Edo State, Nigeria \\ *Corresponding Author Email: monigbinde@sau.edu.ng; Tel: + 2348035230461
}

\begin{abstract}
Adsorption technique has been known to be a very effective method for treatment of heavy metals polluted wastewater, with the advantages of specific affinity, simple design and being user-friendly. However, the high cost of activated carbon commonly used as the adsorbent makes it necessary to explore the use of cheap cellulosic adsorbents. In this study, the adsorptive property of sugarcane bagasse (SB) and orange mesocarp (OM) was investigated. The cellulosic adsorbents were used for the sorption of lead and zinc ions from aqueous solutions. The effects of varying adsorbent dose, varying contact time and initial metal ion concentration on adsorption process of the metals were studied. The results show that both adsorbents (though waste materials) are viable for removal of metals from wastewater. Moreover, SB had higher sorption capacity for zinc (12.95 for SB and 12.68 for OM) while OM had higher sorption capacity for lead ( 9.90 for $\mathrm{OM}$ and 9.48 for $\mathrm{SB}$ ) at optimum dosage. The isothermal studies shows that for lead adsorption, experimental data best fitted the Langmuir isotherm for both adsorbents $\left(\mathrm{R}^{2}\right.$ of 0.9574 for $\mathrm{OM}$ and 0.98 for $\left.\mathrm{SB}\right)$ while the data for zinc adsorption best fitted into Freundlich isotherm with SB $\left(R^{2}\right.$ of 0.9565$)$ and Langmuir isotherm for $O M\left(R^{2}\right.$ of $0.814)$.
\end{abstract}

\section{DOI: https://dx.doi.org/10.4314/jasem.v25i5.14}

Copyright: Copyright $(92021$ Onigbinde and Okeke. This is an open access article distributed under the Creative Commons Attribution License (CCL), which permits unrestricted use, distribution, and reproduction in any medium, provided the original work is properly cited.

Dates: Received: 20 March 2021; Revised: 27 April 2021; Accepted: 07 May 2021

Keywords: Agricultural wastes, sugarcane bagasse, acrylamide monomer, grafting.

The release of heavy metals into our environment as a result of industrial and technological expansion, haphazard rapid urbanization and waste generation from domestic and industrial sources has created a dangerous and negative impact. These have rendered many waters unsafe and hazardous to man health and life and other living resources alongside with it (Jamshaid et al., 2017). Industries discharge different types of heavy metal wastes into the environment at an unprecedented and at a constant increasing rate to the point where it has become a very delicate matter of concern over the last few decades (Anagho et al., 2013). Heavy metals are defined as metals with relatively high densities and atomic weights. They are generally considered as those whose density exceeds 5 $\mathrm{g}$ per cubic centimeter. Most of the elements that falls into this category are naturally occurring, highly water soluble, well-known toxics and carcinogenic agents. They become concentrated as a result of human caused activities and can enter plant, animal, and human tissues via inhalation, diet, and manual handling. Then, they can bind to and interfere with the functioning of vital cellular components. Common examples include Copper, Silver, Zinc, Cadmium, Gold, Mercury, Lead, Chromium, Iron, Nickel, Tin, Arsenic, Selenium, Molybdenum, Cobalt, Manganese, and Aluminum. Some heavy metals are either essential nutrients (typically iron, zinc, and cobalt), or relatively harmless (such as silver and ruthenium), but can be toxic in larger amounts or certain forms. Other heavy metals such as lead mercury and cadmium are highly poisonous and are dangerous pollutants of freshwater reserves because they are non-biodegradable, highly toxic and carcinogenic in nature (Malik, 2017). The releases of these heavy metals in wastewater possess a significant threat to the environment and public health because of their toxicity, bioaccumulation in the food chain and persistence in nature. It is therefore important to explore the possibility of their removal before wastewater discharge. Conventional treatment processes include unit operations like chemical precipitation, coagulation, complexation, ion exchange, solvent extraction, foam flotation, electrodeposition, sedimentation, screening, filtration, membrane separation and adsorption using activated carbon or cellulosic adsorbents from agricultural waste (Abdel-Raouf and Abdel-Raouf, 2017). Adsorption has been considered as a user-friendly, effective purification and separation method for the removal of heavy metals from industrial wastewater with the advantages of specific affinity, low cost and simple design. Adsorption is a surface phenomenon which involves the accumulation of a substance (the adsorbate) on the surface of another substance (the 
adsorbent) (Sanna, 2014). Bioadsorption occurs when biological materials are used, causing a passive physico-chemical interaction between the charged surface groups of the biological material and ions in solution (Fatoye and Onigbinde, 2020). For adsorption process activated carbon is commonly used. But, due to its high cost of production, agricultural by-products are considered very useful alternative and they are environmentally friendly and have efficient adsorption properties (Jamshaid et al., 2017; Muhammad, et al., 2011).

This paper presents a preliminary work focused on the use of unmodified cellulosic adsorbents from agricultural waste to remove heavy metals from aqueous solution as a means of exploring the unutilized potentials of these abundantly available, low cost, and biodegradable bioadsorbents with a view to create wealth from waste.

\section{MATERIALS AND METHODS}

Sugarcane bagasse collection and preparation: The sugarcane was gotten from Ebelle market in Edo state. The bagasse was obtained after extracting the juice from the sugarcane by pounding it and squeezing out the juice. The bagasse was soaked in water for 3 days with its water changed every 24 hours respectively. It was sun dried for 3 days and oven dried for 6 hours at $60^{\circ} \mathrm{c}$ before grinding them into powder.

Orange mesocarp collection and preparation: The orange was gotten from Orie market in Imo state. The orange mesocarp was gotten by sucking the orange fruit, carefully removing endocarp and leaving behind the mesocarp. The mesocarp was properly washed and sun dried for 48 hours. After sun drying the mesocarp was oven dried for 6 hours at $60^{\circ} \mathrm{c}$ before grinding.

Grinding and Sieving: Both the orange mesocarp and sugarcane bagasse were grinded separately with an electric blender (Nuvolexus blender, India). These samples in powdered form were sieved simultaneously using a 600 micron standard sieve.

Batch adsorption: Adsorption experiment was carried out by mechanical agitation at room temperature. Sorption was carried out by stirring $0.2 \mathrm{~g}$ of unmodified cellulose (orange mesocarp and sugarcane bagasse) for $30 \mathrm{mins}$ in $25 \mathrm{ml}$ solution containing $20 \mu \mathrm{gml}^{-1}$ ions of Zinc and Lead. After filtration the remaining metal ions in the filtrate were determined using AAS. The extent of uptake and retention capacity of the unmodified cellulose are then determined. Similar measurements were carried out by using various initial concentration of Zinc and Lead ions.
Kinetic studies: The batch adsorption kinetic studies was carried out by agitating $0.2 \mathrm{~g}$ of the adsorbent in $25 \mathrm{ml}$ solution of known concentration of the metals $\left(\mathrm{Zn}^{2+}, \mathrm{Pb}^{2+}\right)$ at a given time with an initial $\mathrm{pH}$ of between 6.0 and 6.3. After filtering, $15 \mathrm{ml}$ of the filtrate solution was collected using a $20 \mathrm{ml}$ sample bottle at predetermined time interval $(5,10,20,30,40,50$, and $60)$ then filtered rapidly. The metal ion concentration in the filtrate was determined using AAS. The amount of metal ion adsorbed by the adsorbent was gotten as the difference between the initial and final ion concentration of the solutions. These were done for both orange mesocarp and sugar cane bagasse.

Equilibrium isotherm studies: For the isotherm studies, $0.2 \mathrm{~g}$ of the adsorbents was interacted with $25 \mathrm{ml}$ of the adsorbent solution $\left(\mathrm{Zn}^{2+}, \mathrm{Pb}^{2+}\right)$ with a predetermined concentration range $(50-200 \mathrm{mg} / \mathrm{L})$. The reaction was continuously agitated for $30 \mathrm{mins}$. After 30 minutes of interaction, the solution was filtered, the residual concentration and adsorption capacity were determined.

The percentage removal $(\% \mathrm{R})$ and the amount adsorbed (Qe) were calculated using:

$$
\begin{array}{r}
\% \mathrm{R}=\frac{100 C o-C t}{C o} \\
\mathrm{Qe}=\frac{(C o-C e) V}{W}
\end{array}
$$

Where $C_{o}$ and $C_{e}$ are the initial and equilibrium concentrations $(\mathrm{mg} / \mathrm{L})$ respectively, $\mathrm{Ct}$ is the concentration at time, $\mathrm{t}, \mathrm{V}$ is the volume of the solution $(\mathrm{L})$ and $\mathrm{W}$ is the mass in grams ( $\mathrm{g}$ ) of dry adsorbent used (Okeke, 2017).

\section{RESULTS AND DISCUSSION}

Effect of varying adsorbent weight on metal ions adsorption: The availability and accessibility of adsorption site is adsorbent dose controlled (Agbozu and Emoruwa, 2014).The effect of mass of adsorbent on lead and zinc using the cellulosic material was investigated at varying adsorbent weight from 0.1 to $0.5 \mathrm{~g}$ per $25 \mathrm{ml}$ of metal ion solutions. Figure 1 below shows the graphical presentation of the effect on variation of adsorbent weight. It can clearly be deduced that the sorption capacity decrease with increase in adsorbent weight. However, the comparism of the ions shows that zinc is highly adsorbed than lead for both adsorbents used.

Effect of varying contact time on metal ions adsorption: The adsorption experiments were carried out at different time intervals $(10,20,30,40,50$ and $60 \mathrm{mins})$. The result of the effect of contact time on 
adsorption capacity (Qe) was graphically captured in figure 2. Adsorption capacity was seen to slightly increase with increasing contact time. Optimum lead adsorption for OM was at 40mins and SB at 10mins while optimum zinc adsorption for OM was at $30 \mathrm{mins}$ and SB also at 10mins. Zinc was also noticed to have highly adsorbed by both adsorbent than lead. The result follows the trend of previous studies (Agbozu and Emoru, 2014).

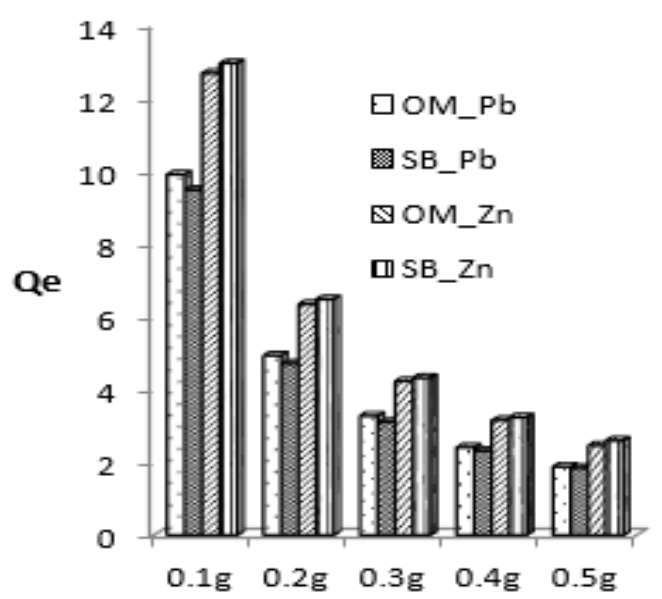

Fig. 1: The adsorptive properties of lead and zinc ions at different adsorbent weight

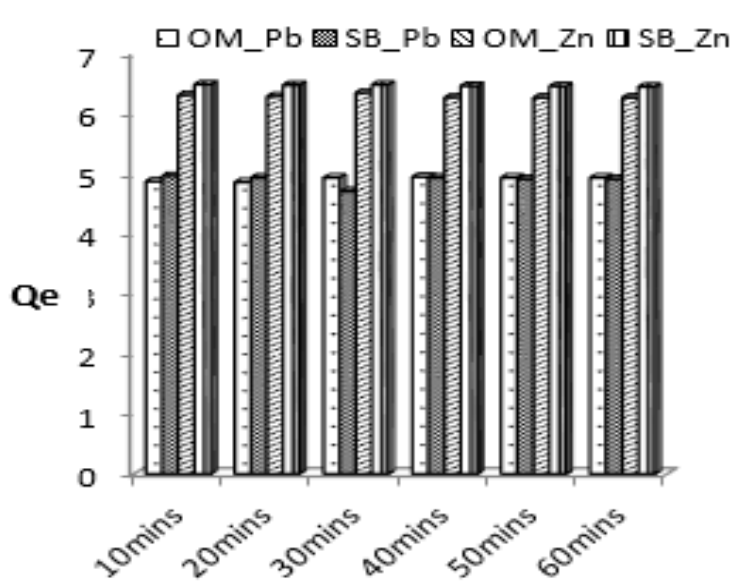

Fig. 2: The adsorptive properties of lead and zinc ions at different contact time

Effect of concentration on the metal ions adsorption: Concentration is another important factor that influences the adsorption properties of adsorbent. For this study adsorption was carried out at different initial metal ions concentrations of 50,100, 150 and $200 \mathrm{mg} / \mathrm{L}$ and figure 3 gives the details of the effect. Lead adsorption capacity only increase with increase concentration for OM but, for zinc both OM and SB show a decrease with increasing concentration. This trend may be due to the saturation of the binding sites on the surface of the adsorbent. However, from literatures it is expected that adsorption capacity increases with increase in initial metal ions concentration (Okiemen and Onyekpa, 2000).

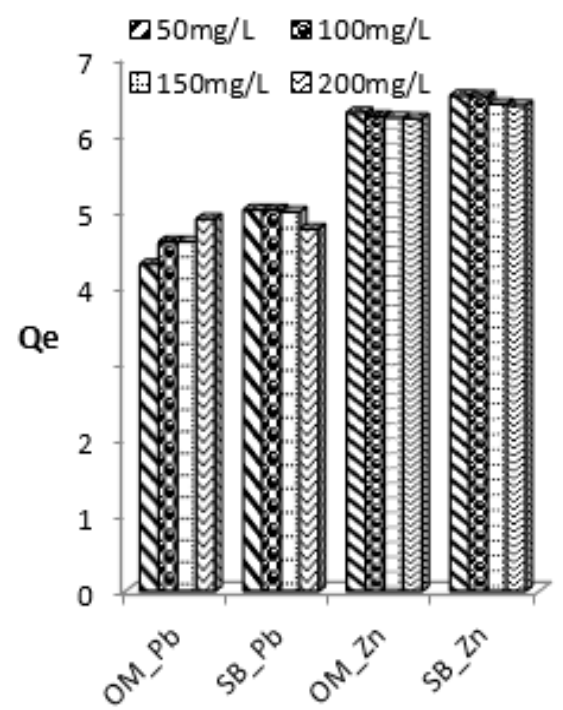

Fig. 3: The adsorptive properties of lead and zinc ions at different concentrations

Isothermal studies: The adsorption isotherms describe the equilibrium studies that give the capacity of the adsorbent and the equilibrium relationships between adsorbent and adsorbate. It actually gives the ratio between the quantity adsorbed and the remaining in solution at fixed temperature at equilibrium. The Langmuir and the Freundlich isotherms are the earliest and the simplest know relationships. The Langmuir isotherm represents the equilibrium distribution of metal ions between the solid and the liquid phases. Langmuir describes adsorption in homogenous phases while Freundlich describe adsorption in heterogeneous surfaces. From the linearized form of their equations their isotherm constants can be graphically deduced.

Table 1: Langmuir and Freundlich isotherm constants obtained

\begin{tabular}{lllllll}
\hline \multicolumn{3}{c}{ Langmuir } & \multicolumn{5}{c}{ Freundlich } \\
\hline Metals & $\mathrm{Qm}$ & $\mathrm{K}$ & $\mathrm{R}^{2}$ & $\mathrm{~N}$ & $\mathrm{~K}_{\mathrm{F}}$ & $\mathrm{R}^{2}$ \\
\hline $\mathrm{OM} \mathrm{Pb}$ & 1.763357 & -2.86414 & 0.9574 & -1.1909 & 3.56287 & 0.9031 \\
$\mathrm{SC} \mathrm{Pb}$ & 0.852079 & -0.5137 & 0.98 & -0.31689 & 85.48698 & 0.9663 \\
$\mathrm{OM} \mathrm{Zn}$ & 1.544879 & -1.02844 & 0.814 & -0.73057 & 9.281112 & 0.554 \\
$\mathrm{SC} \mathrm{Zn}$ & 0.748615 & -4.76561 & 0.8735 & -0.16228 & 0.001093 & 0.9565 \\
\hline
\end{tabular}


A comparism of the coefficient of regression $\left(R^{2}\right)$ for both isotherms is shown in Table 4.9. Lead adsorption best fit into the Langmuir isotherm for both adsorbents ( $\mathrm{R}^{2}$ of $0.9574-\mathrm{OM}$ and $0.98-\mathrm{SC}$ ). But, the data for zinc adsorption best fit into Freundlich isotherm with SC and Langmuir isotherm for OM. The values of correlation coefficients favouring Langmuir isotherm, indicate the formation of monolayer coverage of the metal ions at the external surface of the adsorbent, SC and OM. But for the data following the Freundlich model, this indicates the possibility of an heterogeneous adsorption surface for the adsorbent with sorption sites of different energies and availability (Suteu, 2008).

Conclusion: The need to clean-up heavy metal contaminated wastewater cannot be over emphasized. The result from this study has confirmed the possibility of using OM and SC for adsorption and hence the clarification of heavy metal contaminated water.

\section{REFERENCES}

Abdel-Raouf, MS; Abdul-Raheim, ARM (2017). Removal of Heavy Metals from Industrial WasteWater by Biomass-Based Materials: A Review. J. Pollut. Eff. Cont. 5(180): 1-13.

Agbozu, IE; Emoruwa, FO (2014). Batch adsorption of heavy metals $(\mathrm{Cu}, \mathrm{Pb}, \mathrm{Fe}, \mathrm{Cr}$ and $\mathrm{Cd})$ from aqueous solutions using coconut husk. Afr. J. of Environ. Sci. and Technol. 8(4): 239-246.

Anagho, S; Ketcha, M; Tchuifon, D; Ndi, J (2013). Kinetic and equilibrium studies of the adsorption of mercury (II) ions from aqueous Solution using kaolinite and ketakaolinite clays from Southern Cameroon. Intern. J. of Res. in Chem. and Environ. 3: 1-11.
Fatoye EO; Onigbinde, MO (2020).Dye adsorption with sugarcane bagasse and corn cob. SAU SciTech. J. 5(1): 182-193.

Jamshaid, A; Hamid, A; Muhammad, N; Naseer, A; Ghauri, M; Iqbal, J; Rafiq, S; Shah NS (2017). Cellulose-based Materials for the Removal of Heavy Metalsfrom Wastewater - An Overview. Chem. Bio. Eng. Rev. 4 (4): 1-18.

Malik DS; Jain CK; Yadav AK (2017). Removal of heavy metals from emerging cellulosic low-cost adsorbents: a review. Appl. Water Sci. 7: 21132136.

Muhammad, S; Shah, M; Khan S (2011). Health risk assessment of heavy metals and their source apportionment in drinking water of Kohistan region, northern Pakistan. Microchem. J. 98(2): 334-343.

Okeke, SR (2017). Adsorption studies of heavy metals and organic solids unto cellulosic materials. A final year project submitted to the department of Chemical Sciences, Samuel Adegboyega University, Ogwa, Nigeria.

Sanna, H (2014). Modified nano- and microcellulose based adsorption materials in water treatment. Thesis for the degree of Doctor of Science (Technology). Lappeenranta University of Technology, Lappeenranta, Finland.

Suteu D; Bilba D; Zaharia C; Popescu A (2008). Removal of dyes from textile wastewater by sorption onto ligno-cellulosic materials. Sci. Study \& Res. IX (3): 293-302. 